\title{
Role of Qualified Physicians as Antenatal Care Providers in Reducing Birth Complications in Home-delivered Rural Women in Bangladesh
}

Mohammad Abdullah Heel Kafi ${ }^{1}$, Faisal Ahmmed ${ }^{1}$, Md. Zakiul Hassan ${ }^{2}$, Md. Tariqujjaman ${ }^{1}$, Md. Golam Dostogir G. Harun ${ }^{1}$

1. Epidemiology and Public Health, International Centre for Diarrhoeal Disease Research, Dhaka, BGD 2. Internal Medicine, International Centre for Diarrhoeal Disease Research, Dhaka, BGD

Corresponding author: Mohammad Abdullah Heel Kafi, kafi@icddrb.org

\section{Abstract}

\section{Introduction}

Bangladesh has made significant strides in maternal and neonatal death by ensuring qualified antenatal care (ANC) visits during the pregnancy period of women. To ensure this qualified ANC, the government of Bangladesh has increased the number of qualified physicians and skilled birth attendants at health facilities and encouraged pregnant women to take this eligible ANC during pregnancy. Despite this progress, the majority of deliveries among rural women still occur at home, assisted by traditional birth attendants. These traditional birth attendants at home or even skilled birth attendants at the health facility or home are not always cable of helping women to overcome severe delivery complications. Proper birth preparation before pregnancy through qualified ANC might be a solution here. Taking advice for appropriate birth preparation from a qualified physician (medical doctor) would ensure qualified ANC. In this study, we examined how ANC from a qualified physician, as compared to other trained providers, influences rural women delivering at home to prepare for birth and reduces severe delivery complications.

\section{Methods}

The data of 1554 rural women who delivered at home were extracted from the 2014 Bangladesh Demographic and Health Survey data. A mixed-effects logistic regression model was carried out for the binary delivery complications data, to assess the influence of qualified physicians as ANC providers on delivery complications by adjusting the effect of other socio-demographic covariates and clustering.

\section{Results}

Of the women from rural areas who delivered at home, $42 \%$ reported delivery complications. Those who received ANC from a qualified physician were $32 \%$ less likely (OR $0.68 ; 95 \% \mathrm{CI} 0.50,0.91$ ) to report facing delivery complications as compared to those who had received ANC from other trained or unqualified providers adjusted by socio-demographic determinants in Bangladesh.

Received 01/11/2019

Review began 01/17/2019 Review ended 01/23/2019 Published 01/28/2019

\section{๑) Copyright 2019}

Kafi et al. This is an open access article distributed under the terms of the Creative Commons Attribution License CC-BY 3.0., which permits unrestricted use, distribution, and reproduction in any medium, provided the original author and source are credited.

\section{Conclusions}

Developing a sustained and effective strategy could be a precedent for promoting ANC from qualified physicians for rural women delivering at home, to decrease delivery complications as well as creating healthy environments for safe deliveries.

Categories: Public Health

Keywords: antenatal care, qualified physician, home delivery, rural women, delivery complications, mixed effect, demographic health survey

\section{Introduction}

Globally, maternal mortality due to delivery complications remains unacceptably high, especially among women in low-income countries [1]. Every day, approximately 830 women die from pregnancy and childbirth-related causes and almost $99 \%$ of all maternal deaths occur in low-resource settings [2]. Moreover, complications as a result of the lack of suitable delivery management result in about 10-20 million women worldwide developing physical or mental disabilities each year [3]. Over half of deliveries occur at home in Bangladesh [4]. Although Bangladesh's maternal and infant mortality has declined due to better health care planning throughout the country [5], approximately 5000 women continue to die every year in Bangladesh due to pregnancy or birth-related causes [6]. Most of these delivery-related deaths occur in rural households under the care of unqualified birth attendants [4].

Despite the Government of Bangladesh's initiative to increase the number of qualified physicians and midwives in health facilities [7] in both rural and urban areas, rural women are still reluctant to go to health 
facilities [4] and continue to deliver at home with traditional birth attendants. Although birth attendants can sometimes aid in emergency at-home deliveries, some complications cannot be dealt with without access to health facilities [8]. This causes women living in rural areas to face complications, as they do not have enough knowledge regarding birth preparation. In this regard, in addition to the presence of skilled birth attendants, the woman or her family member also need adequate knowledge on possible complications related to delivery, and this is only achievable through healthier antenatal care visits (ANC) for the duration of the pregnancy [9].

ANC is a clinical process of care provided by health care providers to women during their pregnancy to educate them about various danger signs and symptoms, which can significantly improve their own health and that of their infants during pregnancy, delivery, and in the postpartum period [10]. The World Health Organization (WHO) recommends a minimum of four ANC visits but, regrettably, only about $60 \%$ of all pregnant women worldwide follow this recommendation. In sub-Saharan Africa and South Asia, where maternal mortality is the highest, about $52 \%$ of women in sub-Saharan Africa and $46 \%$ of women in South Asia received at least four antenatal visits [11-12]. Recently, the WHO replaced the four visits ANC-focused model and suggested a minimum of eight visits to a healthcare provider throughout the pregnancy [13]. In 2014, 78\% of women in Bangladesh received at least one ANC session from any provider, whereas in 2004, 2007 , and 2011, it was 58\%, 63\%, and 68\%, showing substantial improvement $[4,14-16]$.

In Bangladesh, ANC providers can be qualified and unqualified based on their academic qualifications. Qualified physicians who received a medical degree approved by the Government of Bangladesh are considered qualified providers. Nurses, midwives, and community health care workers are regarded as trained providers whereas unqualified physicians and NGO workers are considered unqualified ANC providers [4]. In Bangladesh, midwives and medically trained providers are considered qualified providers, but their role in increasing the number of ANC visits and taking birth preparation was small ( only $4 \%$ percentage, from $51 \%$ in 2011 to 55\% in 2014) [4]. Similar to other low and middle-income countries, many women in Bangladesh die each year because of the lack of proper pregnancy and delivery preparedness. This happens mostly in rural areas [4,17-18].

Compared to other providers, qualified ANC providers are better equipped to monitor the status of pregnancy, identify complications associated with pregnancy, and give advice on the steps of birth preparation to prevent adverse pregnancy outcomes [19-21]. In Bangladesh, many studies explored the beneficial effects of receiving the required number of ANC visits from midwives and having skilled birth attendants during deliveries at health facilities as well as at home to reduce delivery complications. However, no extensive research has yet been done to explore the advantageous health effects (if any) of receiving ANC from qualified physicians, especially in the rural areas of Bangladesh. This study, based on nationally representative data, aimed to investigate this while adjusting for other risk factors. Findings from this exercise might be helpful for family planning professionals to take better steps to mitigate maternal and infant mortality due to delivery complications.

\section{Materials And Methods}

\section{Study design}

The data set for this study was extracted from the Bangladesh Demographic and Health Survey (BDHS) of 2014, a nationally representative cross-sectional survey conducted by the National Institute of Population Research and Training (NIPORT), ICF International (USA), and Mitra and Associates between June and November $2014[4]$.

\section{Sampling technique}

The sampling method was a two-stage stratified sample of households. Firstly, 600 enumerations areas (EAs) were selected with probability proportional to size at the first stage, with 207 urban and 393 rural EAs. An EA is defined as a village, a group of small villages, or part of a large village. Second, a systematic sample of 30 households on average was selected per EA to provide statistically reliable estimates of the key demographic and health variables [4]. The 2014 BDHS reported information on 17,863 households through questionnaires with women. Using this, we separated the information of 12,816 women from rural areas and selected 11,666 who had at least one child during the survey. From this group, we extracted information about the place of delivery from 2548 women and finally selected 1554 women who had home births. Written informed consent was obtained from the participants prior to participation in the study and data collection was conducted confidentially. For this study, there was no need for ethical approval since it is based on publicly available secondary data.

\section{Variable assessed and measured}

Our targeted population was rural women who delivered at home. They were asked about their demographic information (age, sex, education level, household head education level, division (administrative area), wealth status) and information on ANC providers. In this study, we categorized the ANC providers into three groups: Qualified physicians, who are actually medical doctors, obtained a Bachelor of Medicine and Bachelor of Surgery (MBBS) degree from Bangladesh government-approved medical colleges, other trained 
providers who was nurses, midwives, paramedics, family welfare visitors, community skilled birth attendants, medical assistants of medical officers, and unqualified providers who worked as community health care providers, untrained traditional birth attendants, non-government organization (NGO) workers, and family welfare assistants, as they were reported in the 2014 BDHS report [4]. We furthermore investigated information on the health-care-seeking behavior of women during their pregnancy such as iron supplements, weight, blood, and urine samples were taken and education on signs of danger during delivery.

\section{Outcome variable measure}

Complications during delivery are generally any problems that pose a risk to the health of the mother and/or baby [4]. In the 2014 BDHS report, there were no details of the various complications; rather, women were asked whether they faced any complications or not during their last birth, preceding the survey. We used this reported information from study participants as our outcome variable. Here, the complications of women included labor pain, the possibility of a premature baby, bleeding, unsafe termination, and pre-eclampsia. Since analyses using the 2014 BDHS data require that sampling weights be applied to ensure the applicability of the survey results at the national and domain levels, we considered the weight variable while constructing the outcome variable. A brief calculation and explanation of the weight variable can be found in the BDHS 2014 report [4].

\section{Statistical analysis}

We analyzed the socio-demographic characteristics of targeted women, such as age, number of children, age at first birth, education, education of the household head, wealth index, division, and occupation, using descriptive statistics. We also explored the health care behavior of the women during their pregnancy, whether they took iron or folic acid supplements, the number of ANC visits, types of ANC providers, whether their last child was wanted at the time, their height, body mass index (BMI; details of this calculation are described elsewhere) [4] and if they faced complications during their last pregnancy. With the outcome variable of whether or not women faced complications at delivery, we calculated the odds ratio using mixedeffect logistic regression to measure the association between the type of ANC provider during pregnancy and reported complications faced at the time of home delivery. We used a mixed-effect logistic regression analysis because, in the BDHS 2014 report, data is nested in nature.

Women's different socio-demographic characteristics were depicted in a conceptual framework to present possible confounders and to find the adjusted effect of ANC providers on complications faced by women. We performed multivariable logistic regression, where the adjustment was done by allowing for these confounder variables. All the analysis was performed using R statistical software (version 3.3.1) and Stata software (Stata/SE 13.1, College Station, TX 77845, USA).

\section{Results}

\section{Demographic characteristics of women who had home deliveries $(n=1554)$}

Among 1554 rural women who delivered at home, about $42 \%$ reported facing complications at the time of their last delivery. Most of these home-delivered rural women (60\%) were aged between 20 and 30 years whereas $16 \%$ were over 30 years old. The prevalence of home delivery was highest in Dhaka (34\%) and Chittagong (19\%) divisions. The majority of these women (52\%) had completed their secondary education and $33 \%$ of women had a partner who had accomplished primary education only. Women from the poorest (according to the wealth index) family accounted for a higher percentage (26\%) of home deliveries whereas the richest accounted for only $7 \%$ (Table 1 ). 


\section{Cureus}

Demographic Characteristics

Women who had taken home delivery

n (\%)

$1554(61)$

Age of the respondents

$15-19$

20-24

25-30

Above 30

Division

Dhaka

Chittagong

Barisal

Khulna

Sylhet

Rajshahi

Rangpur

Education of the respondents

No-education

Primary

Secondary

Higher

Education of the husband/ household

head

No-education

Primary

Secondary

Higher

Wealth index

Poorest

Poorer

Middle

Richer

Richest
369(24)

491(32)

442(28)

252(16)

533(34)

303(19)

102(7)

116(8)

148(9)

155(10)

197(13)

224 (15)

465 (30)

799 (51)

$66(4)$

451 (29)

$516(33)$

473 (30)

114 (8)

401 (26)

392 (25)

380 (24)

283 (18)

98 (7)
Faced complication during delivery at last birth

Yes, n (\%)

No, n (\%)

$653(42)$

901(58)

148 (23)

221 (25)

$199(30)$

$292(32)$

$197(30)$

245 (27)

109 (17)

145 (16)

215 (32)

$318(35)$

131(20)

171 (19)

51 (8)

51 (6)

49(8)

67 (7)

57 (9)

91 (10)

58 (9)

97 (11)

91 (14)

106 (12)

82 (13)

142 (16)

215 (33)

250 (28)

327 (50)

472 (52)

$30(5)$

$37(4)$

211 (32)

240 (27)

205 (32)

311 (35)

191 (29)

282 (31)

$46(7)$

68 (8)

161 (25)

240 (27)

176 (27)

216 (24)

153 (23)

227 (25)

112 (17)

$171(19)$

$51(8)$

$47(5)$

TABLE 1: Demographic and socio-economic information of home delivered rural women and their delivery complication 


\section{Cureus}

Women who reported facing delivery complications, $61 \%$ of them were between 20 and 30 years old. The prevalence of women who faced complications was the highest (33\%) in Dhaka. This may be due to the fact that awareness of reporting of complications was more prevalent in Dhaka, enabling them to take preventive measures for birth preparation before delivery. On the other hand, most of the women (83\%) who completed their primary and secondary education faced complications. We found similar distributional patterns of delivery complications among those women (61\%) whose husbands had completed primary and secondary education. We also noted that the prevalence of delivery complications varied across the wealth status of the respondents. Delivery complications were mostly (25\%) reported by women from poorer families whereas only $8 \%$ of the richest women reported complications (Table 1). Most of the respondents in both categories (home and facility deliveries) had received ANC from qualified physicians during their pregnancy (Figure 1). Women who had received ANC from qualified physicians reported fewer delivery complications than those who consulted unqualified health care providers (Figure 2).

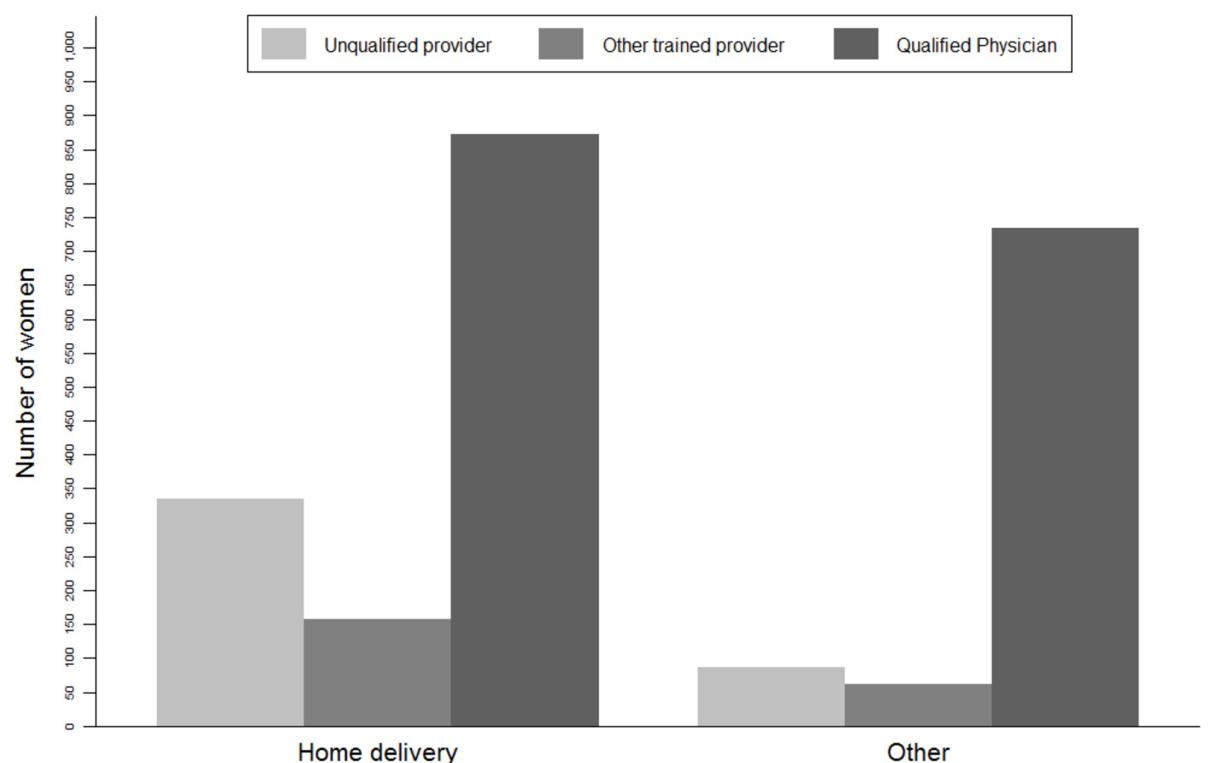

Place of delivery

FIGURE 1: Distribution of ANC provider based on delivery place of the study women

ANC: antenatal care 


\section{Cureus}

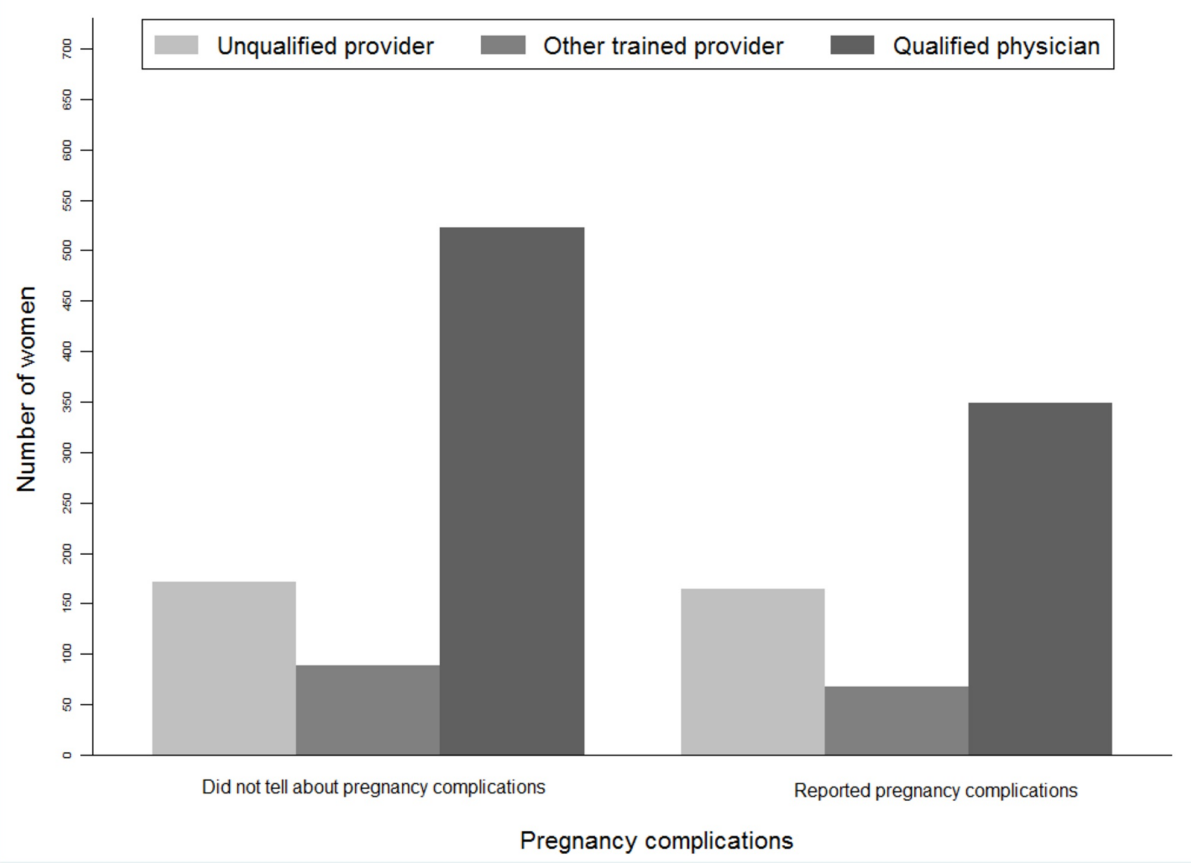

FIGURE 2: Distribution of ANC provider based on reported information regarding delivery complications of the study women

ANC: antenatal care

\section{Characteristics during pregnancy of rural women who had home deliveries $(n=1554)$}

Table 2 provides an indication of antenatal history as well as other birth preparations of rural women who delivered at home. The majority of women (93\%) did not take iron supplements during pregnancy. More than half of the women $(70 \%$ ) had less than four ANC visits, which is lower than previous WHO recommendations of at least four visits (WHO recently changed this number to eight visits) [13]. About $84 \%$ of the women were shorter than $145 \mathrm{~cm}$. Over half of the women (61\%) had normal weight while $27 \%$ were underweight based on the body mass indexed value. Sixty-three percent of the women received ANC from qualified physicians whereas $27 \%$ received ANC from unqualified ANC providers. About $52 \%$ of the women were well-informed on the signs of danger during delivery while $57 \%$ had undergone ultrasound tests during the pregnancy. 


\section{Cureus}

\begin{tabular}{|c|c|c|c|}
\hline \multirow{2}{*}{ Characteristics } & $\begin{array}{l}\text { Women who had taken home } \\
\text { delivery }\end{array}$ & \multicolumn{2}{|c|}{$\begin{array}{l}\text { Faced complication during delivery at last } \\
\text { birth }\end{array}$} \\
\hline & $\mathrm{n}(\%)$ & \multicolumn{2}{|l|}{$\mathrm{n}(\%)$} \\
\hline & & Yes, n (\%) & No, $\mathrm{n}(\%)$ \\
\hline & & $653(42)$ & 901(58) \\
\hline \multicolumn{4}{|l|}{ Took iron tablet } \\
\hline Yes & $68(5)$ & 34(5) & $34(4)$ \\
\hline No & 1443(93) & $597(93)$ & $846(96)$ \\
\hline \multicolumn{4}{|l|}{ ANC attendance } \\
\hline$<4$ times & $1093(70)$ & 404(62) & $689(77)$ \\
\hline$\geq 4$ times & $460(30)$ & 249(38) & $211(23)$ \\
\hline \multicolumn{4}{|l|}{ ANC provider } \\
\hline Unqualified & 422(27) & 210(32) & 212(24) \\
\hline Other trained provider & $160(10)$ & 64(10) & 9/(11) \\
\hline Qualitied doctor & $9 / 2(63)$ & $380(58)$ & 592(66) \\
\hline \multicolumn{4}{|l|}{ Last child intended } \\
\hline Wanted then & $1112(72)$ & $497(76)$ & 615(68) \\
\hline Wanted later & 233(15) & 74(11) & 159(18) \\
\hline Wanted no more & 207(13) & $82(12)$ & 126(13) \\
\hline \multicolumn{4}{|c|}{$145 \mathrm{~cm})$} \\
\hline Yes & 224(14) & 105(16) & 120(13) \\
\hline No & 1319(85) & $544(84)$ & 775(87) \\
\hline \multicolumn{4}{|l|}{ Body mass Index (BIVII) } \\
\hline Underweight & $419(27)$ & $163(25)$ & $256(29)$ \\
\hline Normal weight & 944(61) & 406(63) & $539(60)$ \\
\hline Overweight & $1 / 9(12)$ & $80(12)$ & $99(11)$ \\
\hline \multicolumn{4}{|c|}{ Counsel about danger signs of delivery } \\
\hline Yes & $805(52)$ & $544(83)$ & $261(29)$ \\
\hline No & /49(48) & 109(1/) & $640(/ 1)$ \\
\hline \multicolumn{4}{|l|}{ Take ultrasound test } \\
\hline Yes & $885(5 t)$ & $348(53)$ & $53 /(60)$ \\
\hline No & $669(43)$ & $305(4 h)$ & $364(40)$ \\
\hline
\end{tabular}

TABLE 2: Characteristics of study women during pregnancy

Characteristics during pregnancy of rural women who had home deliveries and faced delivery complications $(n=653)$

Among the women who faced complications, the majority (93\%) of them did not take any iron supplements during their last pregnancy. A lower percentage of women (38\%) who had at least four ANC visits reported facing delivery complications. A higher number of women (50\% (210 out of 422 women)) who had received 


\section{Cureus}

ANC from unqualified providers reported facing delivery complications whereas only 39\% (380 out of 972 women) who had gone to qualified physicians had delivery complications. About $76 \%$ of the women desired the last birth willingly. A higher percentage of women (84\%) who were less than $145 \mathrm{~cm}$ in height reported complications compared to those taller than this height range. Among those who were counseled about the signs of danger during delivery, $83 \%$ reported delivery complications while $53 \%$ of women counseled on delivery risks underwent ultrasound tests.

\section{Factors associated with delivery complications in rural women who delivered at home $(n=653)$}

The factors associated with delivery complications in rural women in home births during their last birth are presented in Table 3. The main factor that we wanted to explore in this study was the effect of qualified physicians' advice on reducing delivery hurdles during ANC visits as compared to advice taken from other types of health care providers. We observed that during ANC visits, women who took advice from qualified physicians were $32 \%$ (OR 0.68 ; $95 \%$ CI $0.50,0.91)$ less likely to face delivery complications as compared to those who had taken advice from unqualified providers adjusted by other confounder variables. This is because as compared to unqualified ANC providers, women who took advice from the qualified physicians got better guidance regarding the symptoms of complications and, therefore, they took better delivery precautions.

\begin{tabular}{|c|c|c|c|c|}
\hline Characteristics & Crude OR(95\% Cl) & P - value & Adjusted OR(95\% Cl) & P-value \\
\hline \multicolumn{5}{|c|}{ Age of the respondents } \\
\hline 15-19 & 1 & & & \\
\hline $20-24$ & 1.05(0.76-1.46) & 0.739 & & \\
\hline $25-30$ & 1.19(0.85-1.67) & 0.294 & & \\
\hline Above 30 & $1.18(0.80-1.74)$ & 0.397 & & \\
\hline \multicolumn{5}{|l|}{ Division } \\
\hline Barisal & 1 & & & \\
\hline Chittagong & $0.74(0.45-1.23)$ & 0.252 & & \\
\hline Dhaka & $0.71(0.43-1.20)$ & 0.206 & & \\
\hline Khulna & $0.65(0.37-1.14)$ & 0.139 & & \\
\hline Sylhet & $0.48(0.28-0.82)$ & 0.008 & & \\
\hline Rajshahi & $0.54(0.31-0.95)$ & 0.033 & & \\
\hline Rangpur & $0.81(0.48-1.37)$ & 0.446 & & \\
\hline \multicolumn{5}{|c|}{ Education of the respondent } \\
\hline No-education & 1 & & 1 & \\
\hline Primary & $1.31(0.88-1.95)$ & 0.180 & $1.50(0.99-2.28)$ & 0.055 \\
\hline Secondary & $1.33(0.91-1.95)$ & 0.134 & 1.66(1.06-2.58) & 0.025 \\
\hline Higher & $1.43(0.76-2.62)$ & 0.27 & 1.95(0.95-4.03) & 0.071 \\
\hline \multicolumn{5}{|c|}{ Education of the husband/ household head } \\
\hline No-education & 1 & & 1 & \\
\hline Primary & $1.08(0.80-1.47)$ & 0.611 & 1.04(0.76-1.42) & 0.783 \\
\hline Secondary & $0.93(0.68-1.29)$ & 0.702 & $0.86(0.62-1.20)$ & 0.393 \\
\hline Higher & $1.09(0.74-1.63)$ & 0.375 & 0.72(0.43-1.18) & 0.192 \\
\hline \multicolumn{5}{|l|}{ Wealth index } \\
\hline Poorest & 1 & & 1 & \\
\hline Poorer & $1.22(0.88-1.69)$ & 0.227 & 1.19(0.85-1.66) & 0.314 \\
\hline
\end{tabular}




\section{Cureus}

\begin{tabular}{|c|c|c|c|c|}
\hline Middle & $1.23(0.87-1.73)$ & 0.239 & $1.18(0.81-1.70)$ & 0.375 \\
\hline Richer & $1.10(0.75-1.61)$ & 0.593 & $1.09(0.72-1.65)$ & 0.664 \\
\hline Richest & $1.40(0.82-2.40)$ & 0.223 & $1.42(0.79-2.54)$ & 0.232 \\
\hline \multicolumn{5}{|l|}{ Took iron tablet } \\
\hline No & 1 & & 1 & \\
\hline Yes & $1.43(0.80-2.60)$ & 0.229 & $1.49(0.73-3.08)$ & 0.272 \\
\hline \multicolumn{5}{|l|}{ ANC attendance } \\
\hline$<4$ times & 1 & & 1 & \\
\hline$\geq 4$ times & $2.21(1.67-2.89)$ & 0.001 & $2.10(1.58-2.78)$ & 0.001 \\
\hline \multicolumn{5}{|l|}{ ANC provider } \\
\hline Unqualified & 1 & & 1 & \\
\hline Other trained provider & $0.87(0.56-1.34)$ & 0.530 & $0.88(0.57-1.37)$ & 0.592 \\
\hline Qualified physician & $0.69(0.52-0.92)$ & 0.014 & $0.68(0.50-0.91)$ & 0.012 \\
\hline \multicolumn{5}{|l|}{ Last child intended } \\
\hline Wanted no more & 1 & & 1 & \\
\hline Wanted then & $1.40(0.96-2.03)$ & 0.075 & $1.54(1.02-2.33)$ & 0.039 \\
\hline Wanted later & $1.02(0.64-1.63)$ & 0.916 & $1.16(0.70-1.93)$ & 0.565 \\
\hline \multicolumn{5}{|c|}{ Height (\% who's height is less than $145 \mathrm{~cm}$ ) } \\
\hline No & 1 & & 1 & \\
\hline Yes & $1.05(0.74-1.50)$ & 0.776 & $1.06(0.74-1.51)$ & 0.744 \\
\hline \multicolumn{5}{|l|}{ Body mass index (BMI) } \\
\hline Normal weight & 1 & & 1 & \\
\hline Underweight & $0.96(0.74-1.27)$ & 0.821 & $0.98(0.74-1.28)$ & 0.892 \\
\hline Overweight & $1.20(0.80-1.79)$ & 0.392 & $1.16(0.77-1.75)$ & 0.456 \\
\hline \multicolumn{5}{|c|}{ Counsel about danger signs of delivery } \\
\hline No & 1 & & 1 & \\
\hline Yes & 17.09(12.31 - 23.72) & 0.001 & 16.33(11.75 - 22.71) & 0.001 \\
\hline \multicolumn{5}{|l|}{ Took ultrasound test } \\
\hline No & 1 & & 1 & \\
\hline Yes & $0.91(0.72-1.16)$ & 0.449 & $1.10(0.78-1.56)$ & 0.568 \\
\hline
\end{tabular}

TABLE 3: Factors associated with complications faced by rural women delivered at home at the time of their last birth within the three years preceding the survey, $2014(n=653)$

We also observed that as compared to women aged 15 to 19 years old, the risk of facing delivery complications in women aged 20 to 24 years, 25 to 30 years, and over 30 years were 1.05 (95\% CI 0.76,1.46), 1.19 (95\% CI 0.85,1.67), and 1.18 (95\% CI 0.80,1.74) times higher. Higher educated women were more likely (OR $1.95 ; 95 \%$ CI $0.95,4.03$ ) to report facing delivery complications as compared to women without education adjusted by age, living place, division, husband's education, and wealth status of the family. This may be due to their awareness and willingness to find a solution to complications. Similar awareness was found among those women (OR 1.04; 95\% CI 0.76, 1.42) whose husbands had at least completed primary education as compared to those whose partner was not educated after adjustment done by the wealth status of the family. Analogously, women with a higher wealth status due to responsiveness and enthusiasm to overcome delivery obstacles were $42 \%$ (OR 1.42 ; $95 \%$ CI $0.79,2.54$ ) more likely to report complications than 
Women who faced more complications during pregnancy were prone (OR 2.10; 95\% CI 1.58, 2.78) to look for further ANC than the recommended number of ANC visits (at least four) from health care providers, to find solutions for their complications, which may be due to their consciousness and awareness. A similar willingness to report delivery complications (OR 1.49; 95\% CI 0.73, 3.08) was found in those women who took iron supplements during pregnancy. Body mass index (BMI) is also a good indicator of women's health. In our study, we observed that women who were overweight (based on the BMI scale) as compared to normal weight reported higher (OR 1.16; 95\% CI 0.77, 1.75) whereas those who were underweight reported less (OR $0.98 ; 95 \%$ CI $0.74,1.28$ ) about their delivery complications. We also found that due to alertness, women who underwent ultrasound tests and were counseled about the signs of danger during delivery were more likely (OR 16.33 95\% CI 11.75, 22.71 and OR $1.1095 \%$ CI 0.78, 1.56) to report delivery complications as compared to those who did not receive the ultrasound test and counseling.

\section{Discussion}

Childbirth in low resource settings, such as rural areas in Bangladesh, especially in the case of home delivery without the presence of a qualified health provider [4], can prove dangerous and increase the chances of delivery complications [22]. Fortunately, the Government of Bangladesh, which was inspired by the earlier success of adding more midwives in health facilities, has again employed more midwives and qualified physicians to overcome the challenges of reducing maternal as well as infant death as part of the Millennium Development Goals [23].

Despite the government's efforts, the availability of qualified birth attendants in rural homes remains low [23] and the lack of sufficient birth preparedness continues to lead to delivery complications [24]. In this situation, women have to prepare from the very beginning of her pregnancy. Hence, more focus on receiving improved ANC visits is needed so that rural women would be able to receive counseling on birth preparedness and make necessary arrangements during home births. Improved ANC would be possible when women receive counseling from qualified physicians at a health facility [25]. Considering this, our study highlighted how the type of health care provider during ANC can play an imperative role in reducing delivery complications based on the nationally representative demographic survey in 2014 .

We found, after analyzing the data, that rural women who had home births during their last birth and received ANC from qualified physicians were $32 \%$ less likely to report delivery complications in comparison to those who consulted unqualified providers. In this case, earlier notification about complications would be possible through ANC from qualified physicians. Similar findings in other settings [26] reported that qualified health care providers during ANC visits led to women experiencing safe deliveries at home. Besides the type of ANC providers, we observed that, like other studies, high ANC attendance [27] led to fewer complications in contrast with those that did not fulfill the required number of ANC visits. Similarly, fewer women who took iron tablets, as advised by qualified physicians during ANC visits, reported fewer delivery complications as other studies reported [28].

Moreover, in our study, when we explored of the pattern of receiving ANC from qualified physicians, we revealed that among all women, only $5 \%$ with higher education reported delivery complications, implying that education may promote receiving ANC from qualified physicians. Therefore, the educational development of women as well as of their husbands is necessary to promote healthier behaviors during pregnancy, to overcome birth complications. More women (45\%) from poor families reported facing delivery complications. Similar findings also suggested that women died during delivery mostly if they were from a poorer family and a rural area. In this regard, besides engaging more skilled birth attendants at rural health facilities, the government of Bangladesh should also focus on raising awareness among rural women about pregnancy and delivery complications, provide free access to health facilities with qualified physicians to take birth preparation, and conduct monthly door-to-door health services. Then, delivery complications among rural home-delivered women might be reduced.

In our study, we used rigorous statistical techniques by considering individual sampling weights and capturing the clustered dependency among them due to the nesting data structure. We applied the mixedeffect logistic regression modeling technique to correctly identify the factors associated with how pregnant women could minimize delivery complications through receiving ANC from qualified physicians, even for home births, which has given our study more strength as compared to other, similar studies. While other biological and social factors are also relevant, this is the first study where we have revealed that receiving ANC from qualified physicians significantly helps women living in rural areas to experience fewer complications and have safe births.

The main limitation of this study was the lack of information regarding the different types of delivery complications women faced during home births. Other limitations include the cross-sectional nature of the data and small sample size, which made determining the causative relationships between ANC providers and delivery complications in home-births difficult. A further study is needed to capture the various biological and socio-economic factors and hurdles women face during home births so the government can take the appropriate and necessary steps to overcome this health problem in Bangladesh. 


\section{Conclusions}

Home-birth complications faced by women in low resource settings, such as rural areas in Bangladesh, are a major public health concern and one of the foremost barriers to achieving the sustainable developmental goal of reducing maternal and infant mortality. The Government of Bangladesh has planned to address this problem by raising awareness and employing more midwives and qualified physicians in rural health facilities. However, these initiatives are facility-based improvements whereas the majority of deliveries continue to occur at home in rural areas, with untrained or unqualified birth attendants. Therefore, improving the availability of quality ANC with qualified physicians in health facilities and encouraging rural women to take ANC visits from a qualified physician during the pregnancy period, to take proper birth preparation, would mitigate the delivery complications and ensure safer births. We anticipate that this outcome will help policymakers and researchers to incorporate and highlight the importance of taking advice from qualified physicians during the pregnancy period in their existing family planning program, to ensure safe births.

\section{Additional Information}

\section{Disclosures}

Human subjects: Consent was obtained by all participants in this study. ICF Macro Institutional Review Board (USA) and National Research Ethics Committee of the Bangladesh Medical Research Council (Dhaka, Bangladesh) issued approval Not applicable. The study uses the data of Bangladesh Demographic and Health Surveys 2014 (BDHS 2014). For this reason, there was no need for ethical approval since it is based on publically available secondary data. The survey data was reviewed and approved by the ICF Macro Institutional Review Board (USA) and National Research Ethics Committee of the Bangladesh Medical Research Council (Dhaka, Bangladesh). Informed consent was obtained from participants while interviewing them. In the dataset, participants were identified with unique numbers but not with any personal information. Animal subjects: All authors have confirmed that this study did not involve animal subjects or tissue. Conflicts of interest: In compliance with the ICMJE uniform disclosure form, all authors declare the following: Payment/services info: All authors have declared that no financial support was received from any organization for the submitted work. Financial relationships: All authors have declared that they have no financial relationships at present or within the previous three years with any organizations that might have an interest in the submitted work. Other relationships: All authors have declared that there are no other relationships or activities that could appear to have influenced the submitted work.

\section{Acknowledgements}

The authors would like to acknowledge the contribution of the BDHS, NIPORT, MEASURE DHS, as well as ICF International teams for their efforts to collect data and give permission to use the Bangladesh Demographic Health Survey, 2014 data. The authors would like to acknowledge the contribution of International Diarrhoeal Diseases Research, Bangladesh (ICDDR,B) to give permission for writing this manuscript. The authors also would like to thank the editors and anonymous reviewers for their helpful comments on the earlier versions of the paper, which certainly improved the content and organization of it.

\section{References}

1. Patton GC, Coffey C, Sawyer SM, et al.: Global patterns of mortality in young people: a systematic analysis of population health data. Lancet. 2009, 374:881-892. 10.1016/S0140-6736(09)60741-8

2. Mannava P, Durrant K, Fisher J, Chersich M, Luchters S: Attitudes and behaviours of maternal health care providers in interactions with clients: a systematic review. Global Health. 2015, 11:36. 10.1186/s12992-0150117-9

3. Filippi V, Ronsmans C, Campbell OM, et al.: Maternal health in poor countries: the broader context and a call for action. Lancet. 2006, 368:1535-1541. 10.1016/S0140-6736(06)69384-7

4. Research NIoP: Bangladesh Demographic and Health Survey 2014. NIPORT, Mitra and Associates, and ICF International, Dhaka, Bangladesh; 2016.

5. Rubayet S, Shahidullah M, Hossain A, et al.: Newborn survival in Bangladesh: a decade of change and future implications. Health Policy Plann. 2012, 27:40-56. 10.1093/heapol/czs044

6. Fottrell E, Osrin D, Alcock G, et al.: Cause-specific neonatal mortality: analysis of 3772 neonatal deaths in Nepal, Bangladesh, Malawi and India. Arch Dis Child. 2015, 100:439-447. 10.1136/archdischild-2014-307636

7. Bogren M, Erlandsson K, Akter HA, et al.: Rights: what prevents midwifery quality care in Bangladesh? A focus group enquiry with midwifery students. BMC Health Serv Res. 2018, 18:639. 10.1186/s12913-0183447-5

8. Moran AC, Wahed T, Afsana K: Oxytocin to augment labour during home births: an exploratory study in the urban slums of Dhaka, Bangladesh. BJOG. 2010, 117:1608-1615. 10.1111/j.1471-0528.2010.02714.x

9. Paul BK, Rumsey DJ: Utilization of health facilities and trained birth attendants for childbirth in rural Bangladesh: an empirical study. Soc Sci Med. 2002, 54:1755-1765. 10.1016/S0277-9536(01)00148-4

10. Al-Ateeq MA, Al-Rusaiess AA: Health education during antenatal care: the need for more . Int J Womens Health. 2015, 7:239-242. 10.2147/Ijwh.S75164

11. Adjiwanou V, LeGrand T: Does antenatal care matter in the use of skilled birth attendance in rural Africa: a multi-country analysis. Soc Sci Med. 2013, 86:26-34. 10.1016/j.socscimed.2013.02.047

12. UNICEF. Female genital mutilation/cutting: a global concern . (2016). https://data.unicef.org/resources/female-genital-mutilationcutting-global-concern/. 
13. Tuncalp, Pena-Rosas JP, Lawrie T, Bucagu M, Oladapo OT, Portela A, Metin Gulmezoglu A: WHO recommendations on antenatal care for a positive pregnancy experience-going beyond survival. BJOG. 2017, 124:860-862. 10.1111/1471-0528.14599

14. Research NIoP: Bangladesh Demographic and Health Survey 2004. NIPORT, Mitra and Associates, and ORC Macro, Dhaka, Bangladesh; 2005.

15. Research NIoP: Bangladesh Demographic and Health Survey 2007. NIPORT, Mitra and Associates, and Macro International, Dhaka, Bangladesh; 2009.

16. Research NIoP: Bangladesh Demographic and Health Survey 2011. NIPORT, Mitra and Associates, and ICF International, Dhaka, Bangladesh; 2013.

17. Rowe AK, de Savigny D, Lanata CF, Victora CG: How can we achieve and maintain high-quality performance of health workers in low-resource settings?. Lancet. 2005, 366:1026-1035. 10.1016/s0140-6736(05)67028-6

18. Ameh C, Msuya S, Hofman J, Raven J, Mathai M, van den Broek N: Status of emergency obstetric care in six developing countries five years before the MDG targets for maternal and newborn health. PloS One. 2012, 7:e49938. 10.1371/journal.pone.0049938

19. Kidney E, Winter HR, Khan KS, Gulmezoglu AM, Meads CA, Deeks JJ, MacArthur C: Systematic review of effect of community-level interventions to reduce maternal mortality. BMC Pregnancy Childb. 2009, 9:2.

20. Tunçalp Ö, Were W, MacLennan C, et al.: Quality of care for pregnant women and newborns-the WHO vision. BJOG. 2015, 122:1045-1049. 10.1111/1471-0528.13451

21. Dowswell T, Carroli G, Duley L, Gates S, Gulmezoglu AM, Khan-Neelofur D, Piaggio G: Alternative versus standard packages of antenatal care for low-risk pregnancy. Cochrane Db Syst Rev. 2015, 6:CD000934. 10.1002/14651858.Cd000934.Pub3

22. Manzi A, Mugunga JC, Nyirazinyoye L, Iyer HS, Hedt-Gauthier B, Hirschhorn LR, Ntaganira J: Costeffectiveness of a mentorship and quality improvement intervention to enhance the quality of antenatal care at rural health centers in Rwanda [Epub]. Int J Qual Health Care. 2018, 10.1093/intqhc/mzy179

23. Azad K, Barnett S, Banerjee B, et al.: Effect of scaling up women's groups on birth outcomes in three rural districts in Bangladesh: a cluster-randomised controlled trial. Lancet. 2010, 375:1193-1202. 10.1016/s01406736(10)60142-0

24. Pasha O, McClure EM, Wright LL, et al.: A combined community- and facility-based approach to improve pregnancy outcomes in low-resource settings: a Global Network cluster randomized trial. BMC Med. 2013, 11:25. 10.1186/1741-7015-11-215

25. Blencowe H, Cousens S, Jassir FB, et al.: National, regional, and worldwide estimates of stillbirth rates in 2015, with trends from 2000: a systematic analysis. Lancet Glob Health. 2016, 4:98-108. 10.1016/S2214$109 x(15) 00275-2$

26. Roro MA, Hassen EM, Lemma AM, Gebreyesus SH, Afework MF: Why do women not deliver in health facilities: a qualitative study of the community perspectives in South Central Ethiopia?. BMC Res Notes. 2014, 7:556. 10.1186/1756-0500-7-556

27. Aryeetey R, Aikins M, Dako-Gyeke P, Adongo PB: Pathways utilized for antenatal health seeking among women in the Ga East District, Ghana. Ghana Med J. 2015, 49:44-49.

28. Pena-Rosas JP, De-Regil LM, Gomez Malave H, Flores-Urrutia MC, Dowswell T: Intermittent oral iron supplementation during pregnancy. Cochrane Database Syst Rev. 2015, 11:CD009997. 10.1002/14651858.CD009997.pub2 